\title{
Verbesserte fluorometrische Methode der 11-Hydroxycorticoid-Bestimmung im Serum zur Diagnostik der Nebennierenrindenfunktion
}

\author{
Von R. Spaethe, Ch. Minneker und H. Otto \\ Aus d.r Mediziniscbcn Klinik und Poliklinik dir Westfäliscbcn Wilhelms-Universität Münster \\ (Dir.ktor: Prof. Dr. W. H. Hauss)
}

(Eingegangen am 6. September 1966)

\begin{abstract}
Es wird eine vereinfachte und verbesserte fluorometrische Bestimmung der 11-Hydroxycorticoide Cortisol und Corticosteron im Serum beschrieben. Die Fluoreszenzintensität kann mit dem Fluorometeraufsatz zum Photometer „Eppendorf“ abgelesen werden. Die Fremdfluoreszenz des Serums wird durch Ablesung zu verschiedenen Zeitpunkten und Errechnung einer „,korrigierten Flưoreszenzintensität“ eliminiert. Empfindlichkeit, Genauigkeit und Richtigkeit der Methode werden diskutiert. Die fluorometrische Bestimmung der 11-Hydroxycorticoide im Serum oder Plasma kann in der oben angegebenen Modifikation auch für das Kliniklaboratorium mit üblicher apparativer Ausrüstung als einfache und zuverlässige Routinemethode gelten.
\end{abstract}

A simplified, improved fluorometric method is described for the determination of the 11-hydroxycorticoids, cortiscl and corticosterone, in serum. The fluorescence intensity can be read from the fluorometer attachment to the "Eppendorf“ photometer. Values are taken at different time intervals and a "corrected fluorescence intensity" is calculated to eliminate the extra fluorescence of the serum. The sensitivity, accuracy, and precision of the method are discussed. The above modification of the fluorometric measurement of 11-hydroxycorticoids in serum or plasma forms a simple and reliable routine method for the normally equipped clinical laboratory.

Die Bestimmung von Nebennierenrindensteroiden im Serum ist in den letzten Jahren methodisch vielfach verbessert und vereinfacht worden. Sie setzt sich in der klinischen Funktionsdiagnostik gegenüber den bisher gebräuchlichen Bestimmungen von Hormonmetaboliten im Harn immer mehr durch.

Erste quantitative Corticoidbestimmungen im Plasma wurden von Nelson und Samuels (1) durchgeführt. Die Methode erforderte eine säulenchromatographische Trennung und kam daher für den klinischen Routinegebrauch nicht in Betracht. Auch das kolorimetrische Porter-Silber-Verfahren (2) erwies sich als zu aufwendig und zeitraubend. Dagegen hat sich die fluorometrische Bestimmung von Plasmacorticoiden in den letzten Jahren als ein großer Fortschritt erwiesen. Das Verfahren beruht auf der Fluoreszenzentwicklung von Cortisol (11 $\beta, 17,21$-Trihydroxy-pregn-4-en-3, 20-dion) und Corticosteron (11 $\beta, 21$-Dihydroxy-pregn-4-en-3, 20-dion) in einem Schwefelsäurereagenz. Quantitative Steroidbestimmungen wurden nach dicsem Verfahren zuerst von Sweat (3) durchgeführt. In der Folgezeit wurde die Methode vor allem von Sileer und Mitarbeitern (4) sowie vOn LE MOOR und Mitarbeitern (5) verbessert und gleichzeitig vereinfacht. Größere Schwierigkeiten bereitete die Ausschaltung störender Fremdfluorogene des Plasmas. Mit spezifischen chromatographischen Methoden war eine mittlere Cortiocoidkonzentration im Serum um $10 \mu \mathrm{g} / 100 \mathrm{~m} l$ ermittelt worden (6-11). Fluorometrisch dagegen wurden infolge der zusätzlichen unspezifischen Fremdfluoreszenz des Plasmas bei gesunden Menschen "Normwerte" um $20 \mu \mathrm{g} /$ $100 \mathrm{ml}(5,12,13)$ und selbst bei Patienten mit totaler Nebennierenrindeninsuffizienz noch Werte um $10 \mu \mathrm{g} /$ $100 \mathrm{ml}(5,14,15)$ gefunden. Es gelang nicht, diese Fremdfluoreszenz durch Waschungen zu eliminieren. In jüngster Zeit ist das Problem jedoch dadurch gelöst worden, da $B$ es gelang, durch Ablesung zu verschiedenen Zeitpunkten die steroid-spezifische Fluoreszenz von der Fremdfluoreszenz rechnerisch $z u$ trennen $(16,17$, 18).
Unsere eigenen Erfahrungen ergaben, daß die Methode von SPENCER-PeET und Mitarbeitern (17) ohne Verlust an Zuverlässigkeit weiter vereinfacht werden kann. Außerdem erwies es sich als zweckmäßig, die von den Autoren für den Gebrauch eines Spektrophotofluorometers angegebene Arbeitsvorschrift für die Ablesung mit dem Fluorometerzusatz eines einfachen Photometers zu modifizieren. Damit kann die fluorometrische Bestimmung der 11-Hydroxycorticoide im Plasma oder Serum als eine einfache und zuverlässige Routinemethode auch für Krankenhauslaboratorien mit üblicher apparativer Ausrüstung gelten.

\section{Methodik}

Reagenzien und Apparatur

Dicblormethan: (Fa. Merck, Nr. 6050) wird ohne weitere Reinigung verwendet.

Konzentrierte Scbıvefelsäure (Fa. Merck, Nr. 731).

Ätbanol: abs. Alkohol (Fa. Merck) wird über $\mathrm{CaO}$ destilliert.

Fluoreszenzreagenz: Äthanol-Schwefelsäure=Gemisch $25: 75$ (v/v). Die Mischung muß vorsichtig und unter Kühlung erfolgen. Das Fluoreszenzreagenz wird täglich frisch zubereitet; es kann aber bei $4^{\circ}$ einige Tage aufbewahrt werden.

Hydrocortison-Standardlösungen: Es wird zunächst durch Lösung von $10 \mathrm{mg}$ Hydrocortison ( $\mathrm{Fa}$. Schering) in $100 \mathrm{ml}$ Äthanol eine Hydrocortison-Stammlösung hergestellt. Die Lösung ist, in dunkler Flasche bei $4^{\circ}$ aufbewahrt, monatelang haltbar. Aus der Stammlösung werden durch weitere Verdünnung mit aqua bidest. Hydrocortison-Standardlösungen von $10 \mu \mathrm{g} / \mathrm{m} l$ und $1 \mu \mathrm{g} / \mathrm{m} l$ hergestellt. Die Lösungen müssen bei Zimmertemperatur angesetzt werden.

Glasgeräte: Es werden $20 \mathrm{ml}$ - und $40 \mathrm{ml}$ =Zentrifugengläser mit Schliffstopfen verwendet. Sämtliche Glasgeräte werden in üblicher Weise gesäubert. Keine Lösung darf mit gummihaltigem Material in Berührung kommen, da Gummi starke Eigenfluoreszenz aufweist.

Scbiittelmascbine: Es wird eine kräftig dreidimensional schüttelnde Apparatur benötigt.

Fluorometrie: Wir benutzten das Photometer "Eppendorf“" mit Fluoreszenzaufsatz. Die Messung exfolgt in rechteckigen Küvetten aus optischem Spezialglas mit einer lichten Breite von $10 \mathrm{~mm}$. Als Primärfilter dient das Filter $\mathrm{Hg} 405+436 \mathrm{~m} \mu$. Die Isolierung der Fluoreszenzstrahlung erfolgt mit dem Filter $500-3000 \mathrm{~m} \mu$. Zur 


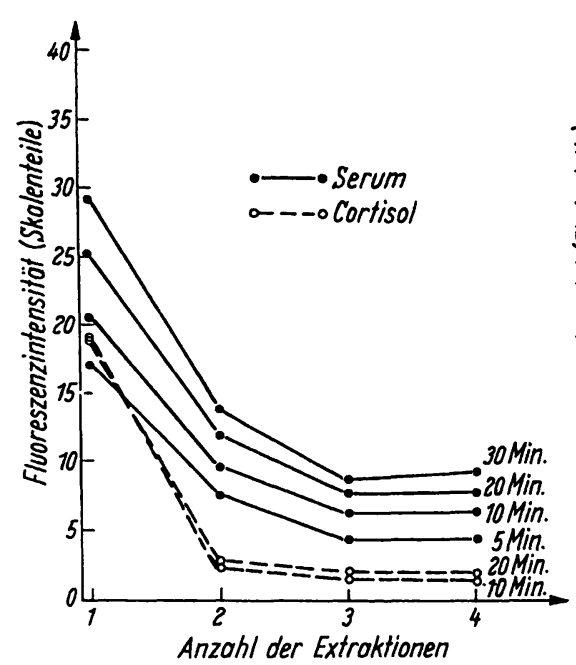

Abb. 1

Abhängigkeit der Fluoreszenzintensität eines Scrums $(\cdot-\bullet)$ und einer wäßrigen Cortisollösung ( $0-0$ ) von der Anzahl der Extraktionen und dem Ablesezeitpunkt

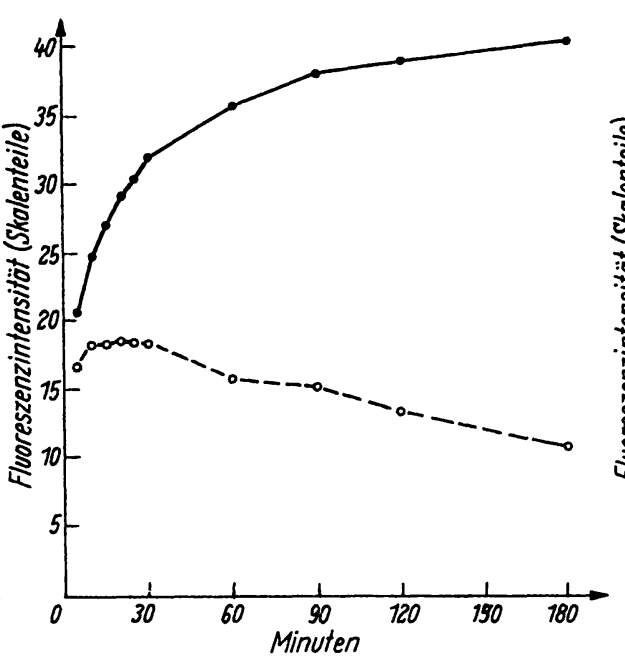

Abb. 2

Fluoreszenzintensität der Extrakte einer wäßrigen Cortisollösung und eines Serums 5-180 Min. nach Zugabe des Fluoreszenzreagenz

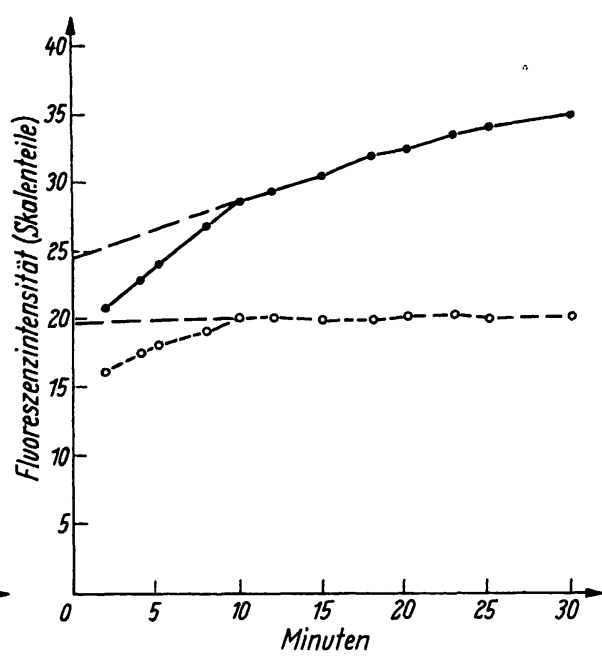

Abb. 3

Fluoreszenzintensität von Extrakten einer wäßrigen Cortisollösung und eines Serums 2-30 Min. nach Zugabe des Fluoreszenzreagenz

Durch Verbinden der 10- und 20-Minutenwerte und Extrapolation dieser Geraden auf die Ordinate wird die korrigierte Fluoreszenzintensität dargestellt
Justierung des Gerätes wird die Lichtmarke mit Hilfe cines grün fluoreszierenden Glasstandards bei Verstärkung 3 vor jeder Ablesung auf 100 Skalenteile der Transmissionsskala eingestellt. Da die Fluoreszenz von Serumextrakten schr viel geringer ist, muß dic Empfindlichkeit des Gerätes erhöht werden; wir verstärkten um 7 Stufen. Die Fluoreszenzintensität wird in Skalenteilen auf der Transmissionsskala abgelcsen.

Das Blut wurde morgens zwischen 8.00 und $9.30 \mathrm{Uhr}$ nüchtern durch Venenpunktion gewonnen und zentrifugiert. Das Serum kann bei $4^{\circ}$ bis zu 4 Tagen ohne Fluoreszenzänderung aufbewahrt werden; anstelle von Serum kann auch Plasma verwendet werden. Für eine Einzelbestimmung benötigt man $4 \mathrm{~m} l$ Serum oder Plasma. Kleinere Mengen lassen - vor allem bei erniedrigter Corticoidkonzentration im Serum - eine sicherc Bestimmung nicht mehr zu.

\section{Arbeitsvorschrift}

In einem $40 \mathrm{~m} l$-Zentrifugenglas mit Schliffstopfen werden $4 \mathrm{~m} l$ Serum mit $15 \mathrm{ml}$ Dichlormethan versetzt und 10 Min. in der Schüttelmaschine extrahiert. Zur sauberen Trennung der Schichten wird anschließend kurz zentrifugiert. $10 \mathrm{ml}$ der Dichlormethanphase werden in ein $20 \mathrm{~m}$-Zentrifugenglas überführt. Der Extrakt kann im verschlossenen Glas bei $4^{\circ}$ bis zu 24 Stdn. aufbewahrt werden. Zur Fluorometrie wird dex Dichlormethan-Extrakt mit $4 \mathrm{ml}$ Äthanol-Schwefelsäure-Gemisch versetzt und 20 Sek. in der Schüttelmaschine geschüttelt, die Phasen trennen sich schnell. $2 \mathrm{ml}$ der unteren Phase werden in eine Fluorometer-Küvette überführt. Die Fluoreszenzintensität wird genau $10 \mathrm{Min}$. und $20 \mathrm{Min}$. nach beendeter Extraktion abgelesen. Ein Leerwert mit $4 \mathrm{ml}$ aqua bidest. wird während des ganzen Arbeitsganges wie eine Serumprobe behandelt. Die Fluoreszenzintensität des Leerwertes wird ebenfalls 10 Min. und 20 Min. nach der letzten Ausschüttelung abgelesen und von den zeitgleichen Werten der Serumproben abgezogen. Vor jeder einzelnen Ablesung der Fluoreszenzintensität einer Serumprobe oder eines Leerwertes muß das Photometer mit Hilfe eines grünfluoreszierenden Glasstandards neu standardisiert werden.

\section{Bereclonung der Ergebnisse}

Aus den abgelesenen Fluoreszenzintensitäten („F. I.“ in Skalenteilen) nach $10 \mathrm{Min}$. und nach $20 \mathrm{Min}$. (Leerwert abgezogen) ergibt sich die Konzentration der 11-Hydroxycorticoide im Serum, wie unten erläutert, nàch folgenden Formeln:

(F. I. 10 Min. $\times$ 2) - F. I. 20 Min. = F. I. korr.

F. I. korr. $\times$ Faktor $\mathrm{F}=\mu \mathrm{g} 11$-Hydroxycorticoide $/ 100 \mathrm{ml}$

Der Faktor $F$ ergibt sich aus dem Verlauf der Cortisol-Eichkurve.

\section{Untersuchungen zur Methodik}

\section{Fremdfluoreszenz des Serums}

Bei mehrfacher Extraktion derselben Probe einer wäßrigen Cortisollösung läßt sich im zweiten, dritten und vierten Extrakt jeweils noch eine Fluoreszenzintensität von 10 bis $15 \%$ des ersten Extraktes nachweisen. Mißt man in den einzelnen Extrakten die Fluoreszenzintensität zu verschiedenen Zeitpunkten nach Zugabe des Äthanol-Schwefelsäure-Gemisches, so tritt zwischen 10 und 30 Min. praktisch keine Änderung auf. Serumproben verhalten sich anders. Im zweiten Extrakt lassen sich noch 40 bis $50 \%$, im dritten und vierten je etwa $30 \%$ der Fluoreszenz des ersten Extraktes nachweisen. Ablesung $\mathrm{zu}$ verschiedenen Zeitpunkten ergibt eine deutliche Zunahme der Fluoreszenzintensität mit der Zeit. Sie steigt in allen Extrakten zwischen 10 und 30Min. nach Zugabe des Äthanol-Schwefelsäure-Gemisches um 40 bis $50 \%$ an (Abb. 1).

$\mathrm{Da}$ Cortisol selbst eine derartige Zunahme der Fluoreszenz mit der Zeit nicht aufweist, muß angenommen werden, daß die Fluoreszenz von Serumextrakten nur zum Teil durch Cortisol, zum anderen Teil aber durch unspezifische Fluorogene bedingt ist. Dabei überwiegt im ersten Extrakt bei weitem das Cortisol, in den folgenden Extrakten das unspezifische fluorogene Material.

Wir haben das unterschiedliche Verhalten der Fluoreszenz von Cortisol- und von Serumextrakten bis $180 \mathrm{Min}$. nach Zugabe des Fluoreszenzreagenzes geprüft (Abb. 2). Der Extrakt einer wäßrigen Cortisollösung zeigte bis $10 \mathrm{Min}$. einen kräftigen Fluoreszenzanstieg, zwischen 10 und 30 Min. gleiclbbleibende Fluoreszenz und im weiteren Verlauf eine allmähliche Abnabme. Dagegen stieg die Fluoreszenzintensität des Serumextraktes - zunächst steil, dann allmählich abflachend - kontinuierlich an. In weiteren Untersuchungen wurde die Fluoreszenz von Cortisol- und Serumextrakten zwischen 2 und 30 Min. 


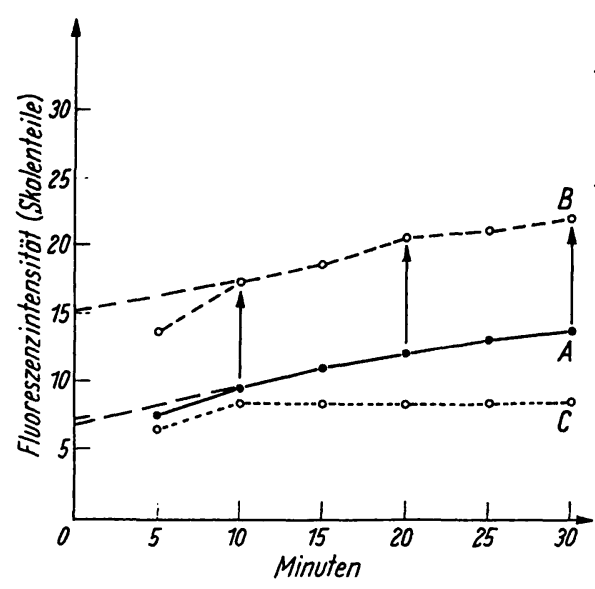

Abb. 4

Fluoreszenzintensität des Extraktes eines Serums ohne und mit Cortisolzusatz; siehe Text

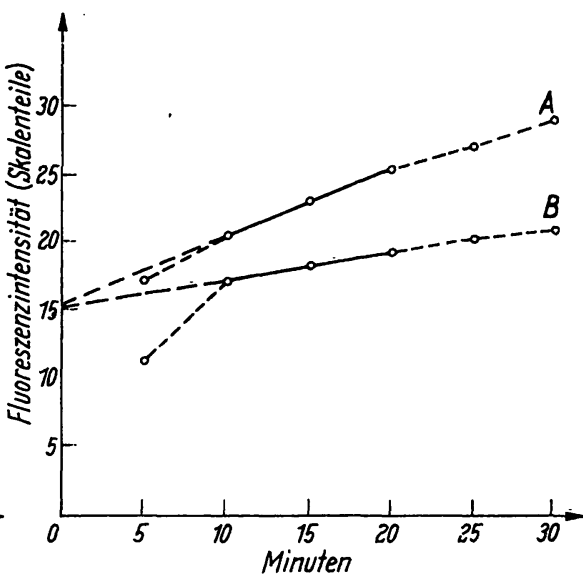

Abb. 5

Vergleich der korrigierten Fluoreszenzintensität von Extrakten mit und ohne $\mathrm{NaOH}-W$ aschung

A: Extraktion mit Dichlormethan ohne B: Extraktion Waschung

B: Extraktion mit Dichlormethan und nachfolgende Waschung mit $0,1 \mathrm{~N} \mathrm{NaOH}$

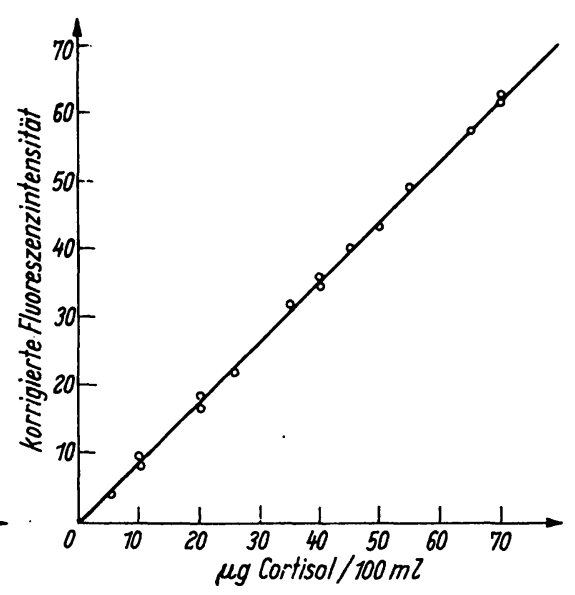

Abb. 6

Cortisol-Eichkurve nach Zugabe des Äthanol-Schwefelsäure-Gemisches in kurzen Intervallen bestimmt. Dabei bestätigte sich die Konstanz der Fluoreszenzintensität des Cortisolextraktes zwischen 10 und $30 \mathrm{Min}$. Gleichzeitig fand sich - zwischen 10 und $25 \mathrm{Min}$. - ein nahezu linearer Anstieg der Fluoreszenzintensität des Serumextraktes mit der Zeit (Abb. 3).

$\mathrm{Da}$ sich die Fluoreszenzintensität des Cortisolextraktes zwischen 10 und 20 Min. niclst ändert, ergibt die Extrapolation der Geraden durch die beiden Ablesewerte auf die Ordinate unmittelbar die. Fluoreszenzintensität des Cortisols während dieses Zeitraums. Die Fluoreszenzintensität des Serums nach $10 \mathrm{Min}$. ist durch Cortisol und durch Fremdfluorogene bedingt; der lineare Anstieg zwischen 10 und 20 Min. beruht allein auf unspezifischer Fluoreszenz. Die Extrapolation dieser Geraden auf die Ordinate muß daher eine korrigierte Fluoreszenzintensität ergeben, die die Fremdfluoreszenz ausschaltet und allein die Cortisolfluoreszenz wiedergibt.

Aus dem in Abbildung 4 dargestellten Versuch ergibt sich, daß Cortisol im Ablesungszeitraum $z$ wischen 10 und $20 \mathrm{Min}$. auch im Serum keine Änderung der Fluoreszenzintensität aufweist. Kurve A stellt die Kurve der abgelesenen Werte eines Serumextraktes dar. Extraktion desselben Serums nach Zugabe von Cortisol ergibt im ganzen Ablesungszeitraum eine parallel verschobene Kurve (B). Die Differenzkurve aus B-A (Kurve C) entspricht, wie erwartet, der Ablesungskurve einer reinen wäßrigen Cortisollösung.

Im übrigen spricht auch der Kurvenverlauf bei Patienten mit totaler Nebennierenrinden-Insuffizienz eindeutig dafür, daß der Fluoreszenzanstieg zwischen 10 und 20 Min. durch unspezifische Fluorogene hervorgerufen ist, und daß die Extrapolation der Geraden durch die beiden abgelesenen Fluoreszenzwerte auf die Ordinate die Fluoreszenz des Cortisols ergibt. Die Gerade schneidet nämlich bei diesen Patienten die Ordinate regelmäßig im Nullpunkt oder bei gering positiven Werten.
Die von DE MOOR und Mitarbeitern (5) empfohlene Waschung des Dichlormethan-Extraktes mit Natronlauge zur Verminderung der Fremdfluoreszenz stellt auch nach unserer Erfahrung - übereinstimmend mit $(14,17)$ - keine methodische Verbesserung dar. Wie in Abbildung 5 gezeigt, ist der Gehalt an unspezifischen Fluorogenen im gewaschenen Extrakt (B) im Vergleich zum ungewaschenen (A) zwar vermindert, aber nicht beseitigt. Die Extrapolation der Ablesungskurven beider Extrakte ergibt dieselbe korrigierte Fluoreszenzintensität.

Zur Bestimmung der korrigierten Fluoreszenzintensität ist die graphische Extrapolation unnötig. Die Berechnung kann vielmehr in der angegebenen Weise anhand der oben gegebenen Formel erfolgen.

\section{Eicbkurve}

Von wäßrigen Cortisollösungen verschiedener Konzentration wurde, jeweils in Mehrfachbestimmungen, die Fluoreszenzintensität gemessen und mit Hilfe dieser Werte eine Eichkurve aufgestellt (Abb. 6).

Aus der Kurve ergibt sich, daß die korrigierte Fluoreszenzintensität im Bereich zwischen 0 und $70 \mu \mathrm{g} / 100 \mathrm{~m} l$ Cortisol eine lineare Funktion der Cortisolkonzentration ist. Für jeden Einzelwert wurde der Faktor

$$
\mathrm{F}=\frac{\text { Cortisolkonzentration (in } \mu \mathrm{g} / 100 \mathrm{~m} / \text { ) }}{\text { korrigierte Fluoreszenzintensität (in Skalenteilen) }}
$$

berechnet. Durch Multiplikation der korrigierten Fluoreszenzintensität mit dem Faktor $F$ erhält män die Konzentration der 11-Hydroxycorticoide in $\mu \mathrm{g} / 100 \mathrm{ml}$. Die Aufstellung der Eichkurve und die Berechnung des Faktors $\mathrm{F}$ muß für jedes Fluorometer gesondert erfolgen. Mit unserem Gerät ergab sich ein Faktor $F=1,13$.

\section{Spezifität}

Bedenken gegen die Spezifität der fluorometrischen Bestimmung der 11-Hydroxycorticoide wurden von mehreren Seiten (19-22) vor allem wegen der Fremdfluorès- 
Tab. 1 Standardabweichungen von Doppelbestimmungen

\begin{tabular}{|c|c|c|c|c|c|}
\hline Konzentrationsbereich in $\mu \mathrm{g} / 100 \mathrm{ml}$ & $0-5,0$ & $5,1-10,0$ & $10,1-20,0$ & $20,1-30,0$ & über 30 \\
\hline Anzahl der Doppelbestimmungen & 54 & 48 & 79 & 53 & 30 \\
\hline Standardabweichungen s der Doppelbestimmungen & 0,4 & 0,5 & 0,6 & 0,7 & 0,9 \\
\hline
\end{tabular}

zenz geltend gemacht. Zusätzliche Waschungen mit Petroläther $(5,13,23)$, Trimethylpentan (24) oder Natronlauge $(5,13,19,24,25)$ konnten die unspezifischen Fluorogene nur teilweise eliminieren und stellten daher keine grundsätzliche Verbesserung dar. Die Berechnung der korrigierten Fluoreszenzintensität macht Waschungen dieser Art, wie oben dargestellt (Abb. 5), überflüssig. In dieser Hinsicht decken sich unsere Befunde mit denen von SPENCER-PeET und Mitarbeitern (17). Unter den beschriebenen Bedingungen werden Cortisol und Corticosteron gemeinsam erfaßt. Andere natürliche und synthetische Steroide zeigen dagegen keine oder nur sehr geringe Fluoreszenz (5, 13, 14, 18, 26).

\section{Genauigkeit}

Die Genauigkeit der Methode wurde durch die Errechnung der Differenz von Doppelbestimmungen nach der Formel von SNEdECOR (27) überprüft:

$$
\mathrm{s}=\sqrt{\frac{\sum \mathrm{d}^{2}}{2 \mathrm{~N}}}
$$

Dabei bedeuten: $s=$ Standardabweichung, $d=$ Differenz der Einzelwerte einer Doppelbestimmung, $\mathrm{N}=$ Anzahl der Doppelbestimmungen.

In Tabelle 1 sind die Anzahl der Doppelbestimmungen und die zugehörigen Standardabweichungen der Doppelbestimmungen für verschiedene Konzentrationsbereiche angegeben.

\section{Ricbtigkeit}

Die Richtigkeit der Methode ergibt sich aus Wiederfindungsversuchen. Bei Zugabe von 0,02 bis $0,7 \mu \mathrm{g}$ Cortisol zu 4,0 ml Serum wurden im Mittel von 34 Doppelbestimmungen $91,6 \%$ wiedergefunden. Aus wäßrigen Lösungen wurden 0,05 bis $4,0 \mu \mathrm{g}$ Cortisol in 52 Doppelbestimmungen zu 95,4\% wiedergefunden.

\section{Empfindlichleit}

Die größte Empfindlichkeit der fluorometrischen 11Hydroxycorticoidbestimmung wird mit einem ÄthanolSchwefelsäuregemisch 25:75 (v/v) und mit einer optimalen Filterkombination des Fluorometers (Primärfilter $467 \mathrm{~m} \mu$, Sekundärfilter $528 \mathrm{~m} \mu$ ) erreicht $(24,28)$. Wir verwendeten die handelsüblichen Filter für den Fluorometeraufsatz zum Photometer „Eppendorf“ und prüften die Empfindlichkeit unserer Modifikation nach BRown, Bulbrook und Greenwood (29). Dabei wird die kleinste Corticoidkonzentration, die noch von Null unterschieden werden kann, nach folgender Formel errechnet: $\frac{t \cdot s}{\sqrt{N}}$ Es bedeuten $t=$ Student's $t ; N=$ Anzahl der Einzelbestimmungen, $s=$ Standardabweichung.
Für unsere Bestimmungen hatte sich ein niedrigstes $s=0,4$ (Tab. 1) errechnet. Dabei können in einer Einzelbestimmung noch $1,03 \mu \mathrm{g} / 100 \mathrm{ml}$, bei Doppelbestimmung $0,73 \mu \mathrm{g} / 100 \mathrm{ml}$ gemessen werden $(\mathrm{p}=0,01)$. Bei so geringer Konzentration kann die Fehlerbreite 100\% betragen.

\section{Ergebnisse von 11-Hj'droxycorticoid-Bestimmungen in Fuman- serum}

Bei 54 endokrin-gesunden männlichen und weiblichen Patienten im Alter von 16 bis 74 Jahren, die nicht an einer Leber- oder Nierenfunktionsstörung oder an einer schweren Allgemeinerkrankung litten, lag dic Konzentration der 11-Hydroxycorticoide im Nüchternserum $z w i s c h e n$ 5,3 und $15,0 \mu \mathrm{g} / 100 \mathrm{ml}$. Sämtliche Bestimmungen wurden in Doppelwerten ausgeführt. Es errechnete sich ein Mittelwert mit Standardabweichung von $10,5 \pm 2,6 \mu \mathrm{g} / 100 \mathrm{ml}$.

Bei 5 Patienten mit diagnostisch gesicherter primärer Nebennierenrindeninsuffizienz wurde ein Mittelwert von $1,5 \pm 1,3 \mu \mathrm{g} / 100 \mathrm{~m} l$ gefunden. Bei Patienten, die aus nicht-endokriner Indikation unter Behandlung mit Glucocorticoiden standen, war die 11-Hydroxycorticoid-Konzentration im Nüchternserum abhängig von der Höhe der Dosierung und der Dauer der Behandlung. Über diese Befunde haben wir an anderer Stelle ausführlich berichtet (30). Nach Stimulierung der Nebennierenrinden mit intravenöser Injektion von $25 \mathrm{IE}$ Corticotropin $\beta^{1-24}$ („Synacthen ", Fa. CIBA) steigt nach unserer Erfahrung $(30,31)$ der 11-Hydroxycorticoidspiegel im Serum innerhalb von $30 \mathrm{Min}$. auf einen mittleren Wert von $21,6 \pm 4,2 \mu \mathrm{g} / 100 \mathrm{ml}$ an.

\section{Diskussion}

Die wichtigsten methodischen Verbesserungen der fluorometrischen 11-Hydroxycorticoid-Bestimmung im Serum bzw. Plasma sind kürzlich von Spencer-PeET und Mitarbeitern (17) bereits zusammengefaßt worden. Im Prinzip hat sich die von diesen Autoren angegebene Methode auch in unserem Laboratorium bewährt. Vor allem können wir anhand unserer Befunde bestätigen, daß sich die Fremdfluoreszenz des Serums durch Ablesung zu verschiedenen Zeitpunkten auf einfache Weise rechnerisch eliminieren läßt, so $\mathrm{da} ß$ Waschungen des Serums oder des Dichlormethanextraktes überflüssig werden.

Die Arbeitsvorschrift von Spencer-PeEt und Mitarbeitern ist für die Verwendung eines Spektrophotofluorometers angegeben. Für die klinische Routinediagnostik erwies es sich daher als zweckmäßig, eine Modifikation für einfachere Einrichtungen zur Fluoreszenzmessung 
zu erarbeiten. Dabei ergaben sich zugleich einige Verbesserungen und Vereinfachungen des Arbeitsganges. Für die Ausschüttelung des Plasmas mit Dichlormethan erwies sich eine Dauer von $10 \mathrm{Min}$. als ausreichend; die Extraktion von Cortisol aus wäßriger Lösung erfolgt in dieser Zisit praktisch quantitativ. Im Serum wird eine Restfluoreszenz - die möglicherweise nicht durch 11-Hydroxycorticoide bedingt ist - auch durch langdauernde Ausschüttelung nicht erfaßt.

Im Gegensatz zu SPENCER-PeET und Mitarbeitern fanden wir eine Konstanz der Fluoreszenzintensität von Cortisolextrakten nur $z$ wischen 10 und $30 \mathrm{Min}$., so daß wir die 10. und 20. Min. als günstigste Zeitpunkte der Ablesung wählten. Die gleichzeitige Aufarbeitung eines Cortisol-Standards zur Eichung des Fluorometers vor jeder Messung kann entfallen, da unsere Cortisol-Eichkurve bei Zimmertemperatur gut reproduzierbar ist, und es daher genügt, wenn für die Justierung des Ablesegeräts ein grün-fluoreszierender Glasstandard benutzt wird. Die Konzentration der 11-Hydroxycorticoide im Ausgangsmaterial wird zweckmäßig dadurch errechnet, da $\beta$ die korrigierte Fluoreszenzintensität mit einem aus der Cortisol-Eichkurve erhaltenen Umrechnungsfaktor multipliziert wird. Um auch erniedrigte $11-$ Hydroxy-
corticoid-Konzentrationen im Serum genau erfassen zu können, sind für jede Einzelbestimmung allerdings $4 \mathrm{ml}$ Serum erforderlich. Dies stellt einen gewissen Nachteil der beschriebenen Modifikation dar, der durch die - im Vergleich zu einem Spektrophotofluorometer - geringere Empfindlichkeit des Fluorometeraufsatzes zum Photometer „Eppendorf" bedingt ist. Die Empfindlichkeit, Genauigkeit und Richtigkeit der Methode werden jedoch nicht beeinträchtigt.

Die von uns ermittelte durchschnittliche Konzentration der 11-Hydroxycorticoide von $10,5 \pm 2,6 \mu \mathrm{g} / 100 \mathrm{~m} l$ im Nüchternserum von endokrin-gesunden Erwachsenen stimmt mit den Werten überein, die mit aufwendigeren chromatographischen (6-11) und fluorometrischen Verfahren $(15,16,19,22,23,32,33)$ erhalten wurden. Mit der angegebenen Modifikation der fluorometrischen 11-Hydroxycorticoidbestimmung werden Cortisol und Corticosteron gemeinsam erfaßt. Die beiden Hormone kommen im menschlichen Serum unter physiologischen Bedingungen im Verhältnis von etwa $6: 1$ vor. Eine Trennung und isolierte Bestimmung von Cortisol ist prinzipiell möglich (31-33), aber umständlich und bringt für die klinische Routinediagnostik der Nebennierenrindenfunktion keinen wesentlichen Vorteil.

\section{Literatur}

1. Nelson, D. H. und L. T. Samuels, J. clin. Endocrin. 12, 519 (1952). - 2. Silber, R. H. und C. C. Porter, J. biol. Chem. 210, 923 (1954). - 3. Sweat, M. L., Analyt. Chem. 26, 773 (1954). 4. Silber, R. H., R. D. Busch und R. Oslapas, Clin. Chem. 4, 278 (1958). - 5. De Moor, P., O. Steeno, M. Raskin und A. HeNdrix, Acta endocr. (K'hon) 33, 297 (1960). - 6. BoNDy, P. K. und G. V. Upton, Proc. Soc. Exp. Biol. (N. Y.) 94, 585 (1957). 7. Braunsberg, H. und V. H. T. James, J. Endocrin. 21, 327 (1960). - 8. Dunkelman, S. S., B. Fairhurst, J. Plager, J. clin. Endocr. 24, 832 (1964). - 9. FEHÉR, T., O. KOREF und M. H. KAZIK, Acta endocr. 51, 429 (1966). - 10. Lewrs, B., J. clin. Path. 10, 148 (1957). - 11. Tamm, J. und H. Starlinger, 4. Symp. Dtsch. Ges. f. Endokrin. Springer Verlag Berlin-GöttingenHeidelberg 1957, S. 585. - 12. GantT, C. L., D. E. Maynard und G. G. Hamwr, Metabolism 13, 1327 (1964). - 13. Staht, F., I. Hertling und G. KNAppe, Acta biol. med. germ. 10, 480 (1963). - 14. Mattingly, D., J. clin. Path. 15, 374 (1962). 15. Stewart, C. P., F. Albert-Recht und L. M. Osman, Clin. chim. Acta 6, 696 (1961). - 16. Dörner, G. und F. Staht, Dtsch. med. Wschr. 90, 1917 (1965). - 17. Spencer-PeEt, J., J. R. Daly und V. SMIth, J. Endocrin. 31, 235 (1965). - 18. StAHL, F. und
G. DöRnER, Acta biol. med. germ. 13, 424 (1964). - 19. BraunsBERG, H. und V. H. T. JAMES, J. Endrocrin. 25, 309 (1962). 20. Daly, J. R. und J. SPenCER-PEet, J. Endocrin. 30, 255 (1964). - 21. Doe, R. P., R. Fernadez und U. S. SeaL, J. clin. Endocr. 24, 1029 (1964). - 22: RuDD, B. T., P. SAMpSON und B. N. Brooke, J. Endoctin. 27, 317 (1963). - 23. VAN der Vies, J., Acta endocr. 38, 399 (1961). - 24. SteEnBuRg, R. W. und B. H. Thomasson, J. clin. Endocr. 24, 875 (1964). - 25. Bethge, H., W. WinkelmanN und H. ZimmermanN, Klin. Wschr. 43, 1274 (1965). - 26. De Moor, P., P. Osinski, R. Deckx und O. Steeno, Clin. chim. Acta 7, 475 (1962). - 27. SNEDECOR, G. W., Queries Biometrics 8, 85 (1952). - 28. Braunsberg, H. und V. H. T. JAMEs, Analyt. Biochem. 1, 452 (1960). - 29. Brown, J. B., R. D. Bulbrook und F. C. Greenwood, J. Endocrin. 16, 41 (1957). - 30. Spaethe, R., C. Minneker und H. Otto, Dtsch. med. Wschr. 91, 1483 (1966) - 31. Orro, H., C. MINNEKER und R. SPAETHE, Dtsch. med. Wschr. 91, 934 (1966). - 32. VAN DER WaL, B., A. L. Israels, J. F. Janssen und D. DE Wied, Acta endocr. 38, 392 (1961). - 33. Vermeulen, A., M. VAN DER StraEten, J. clin. Endocr. 24, 1188 (1964).

Priv. Doz. Dr. H. Otto, 44 Münster, Westring 3 